Boston University School of Law

Scholarly Commons at Boston University School of Law

Faculty Scholarship

2012

\title{
Effect of Financial Relationships on the Behaviors of Health Care Professionals: A Review of the Evidence
}

Christopher Robertson

Boston University School of Law

Susannah Rose

Aaron Kesselheim

Follow this and additional works at: https://scholarship.law.bu.edu/faculty_scholarship

Part of the Evidence Commons, Health Law and Policy Commons, and the Medical Jurisprudence Commons

\section{Recommended Citation}

Christopher Robertson, Susannah Rose \& Aaron Kesselheim, Effect of Financial Relationships on the Behaviors of Health Care Professionals: A Review of the Evidence, 40 Journal of Law, Medicine, \& Ethics 452 (2012).

Available at: https://scholarship.law.bu.edu/faculty_scholarship/1119

This Article is brought to you for free and open access by Scholarly Commons at Boston University School of Law. It has been accepted for inclusion in Faculty Scholarship by an authorized administrator of Scholarly Commons at Boston University School of Law. For more information, please contact lawlessa@bu.edu. 


\title{
EFFECT OF FINANCIAL RELATIONSHIPS ON THE BEHAVIORS OF HEALTH CARE PROFESSIONALS: A REVIEW OF THE EVIDENCE
}

\author{
August 1, 2012 \\ forthcoming, \\ Journal OF LAW, Medicine, \& ETHICS (Fall 2012)
}

Christopher Robertson, J.D., Ph.D.

Associate Professor, James E. Rogers College of Law, University of Arizona, and Research Associate, Edmond J. Safra Center for Ethics, Harvard University

Susannah Rose, Ph.D.

Assistant Professional Staff, Cleveland Clinic, and

Fellow, Edmond J. Safra Center for Ethics, Harvard University

Aaron S. Kesselheim, M.D., J.D., M.P.H.

Assistant Professor of Medicine at Harvard Medical School, Division of

Pharmacoepidemiology and Pharmacoeconomics, Department of Medicine, Brigham and Women's Hospital

\begin{abstract}
This paper explores the empirical evidence regarding the impact of financial relationships on the behavior of health care providers, specifically, physicians. We identify and synthesize peer-reviewed data addressing whether financial incentives are causally related to patient outcomes and health care costs. We cover three main areas where financial conflicts of interest arise and may have an observable relationship to health care practices: physicians' roles as self-referrers, insurance reimbursement schemes that create incentives for certain clinical choices over others, and financial relationships between physicians and the drug and device industries. We found a well-developed scientific literature consisting of dozens of empirical studies, some that allow stronger causal inferences than others, but which altogether show that such financial conflicts of interests can, and sometimes do, impact physicians' clinical decisions. Further research is warranted to document the causal relationship of such changes on health outcomes and the cost of care, but the current base of evidence is sufficiently robust to motivate policy reform.
\end{abstract}




\section{Contents}

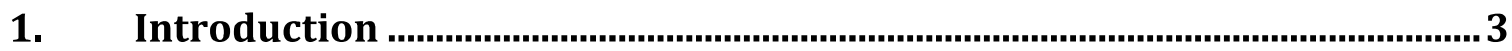

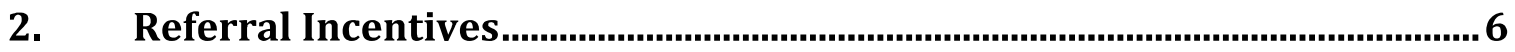

a. Self-Referral For Office Services..........................................................................

b. Referral to Physician-owned Centers ………………………………………….... 14

3. Physician Salary and Financial Incentives............................................. 17

a. Physician Reimbursement Systems .................................................................. 18

b. Effect of Pay-for-Performance Bonuses ............................................................. 23

4. Relationships with the Pharmaceutical and Device Industries ................ 27

a. Direct Financial Inducement in Pharmaceutical Promotion ........................... 29

b. Drug Samples and Physician Prescribing ………………………………………... 35

c. Physicians' Perceptions about Drug and Device Marketing ............................ 38

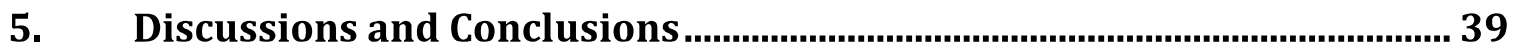

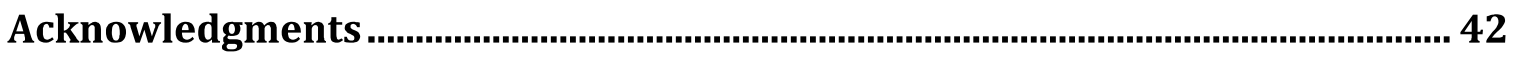




\section{Introduction}

Physicians, scholars, and policymakers continue to be concerned about conflicts of interests among health care providers. There are at least two main types of objections to conflicts of interest. Conflicts of interests may be intrinsically troublesome if they violate providers' fiduciary duties to their patients or they contribute to loss of trust in health care professionals and the health care system. Conflicts of interest may also be problematic in practice if they bias the decisions made by providers, adversely impacting patient outcomes or wastefully increasing health care costs. This latter objection may be observed in differences in the prescriptions written, procedures performed, or costs billed by health care professionals who have conflicting interests, when compared to those that do not have such financial relationships.

Reflecting this second concern, the Supreme Court has said that, "our cases have taught us that there are some unscrupulous physicians who overprescribe when it is sufficiently profitable to do so." ${ }^{1}$ It is not clear, however, whether these are rare outliers on an otherwise healthy system, for which criminal enforcement and other disciplinary procedures would suffice, or whether pervasive conflicts of interests in everyday healthcare are biasing the behaviors of even the honest and dedicated physicians. If this larger concern is borne out by evidence, it would

1. Gonzales v. Raich, 545 U.S. 1, 31, 125 S. Ct. 2195, 2214, 162 L. Ed. $2 d 1$ (2005) (citing United States v. Moore, 423 U.S. 122, 96 S.Ct. 335, 46 L.Ed.2d 333 (1975); United States v. Doremus, 249 U.S. 86, 39 S.Ct. 214, 63 L.Ed. 493 (1919)). 
provide a case for increased and different forms of regulation of conflicting interests.

There are reasons to doubt whether conflicts of interest impact the behaviors of physicians and other health care professionals. First, these professionals have commitments to explicit codes of ethics. For example, the American Medical Association's Code of Medical Ethics specifies that, "under no circumstances may physicians place their own financial interest above the welfare of their patients." ${ }^{2}$ Professionals who strictly adhere to this Code would not consciously alter their medical practice in response to financial incentives.

In addition, the practice of medicine is in part a science, driven by laws of biology and physics. If such laws clearly dictate good medical practices, physicians may be unlikely to deviate from these practices.

According to one commentator, "physicians believe they are invulnerable to undue influence from industry ... because they are convinced that their knowledge of the medical literature makes them impervious to industry influence." ${ }^{3}$ Indeed, in one survey of physicians who received an all-expenses paid trip to a luxury resort to learn about a new drug, a majority of physicians insisted that the trip would "in no

2. American Medical Association Code of Medical Ethics $\S 8.03$, available at $<$ http://www.ama-assn.org/ama/pub/physician-resources/medical-ethics/codemedical-ethics.shtml> (last visited July 12,2012) [hereinafter AMA CODE].

3. P. A. Ubel, "Commentary: How Did We Get Into This Mess?," Conflicts of Interests: Challenges And Solutions In Business, Law, Medicine, And Public Policy, 142, no. 143-49 (Don A. Moore et al. eds., 2005). See also D. Katz, A. L. Caplan and J. F. Merz, "All Gifts Large and Small," American Journal of Bioethics, 3, no. 3, (Summer 2003): 39-46. (collecting sources for the propositions that "Many physicians deny the potential for the receipt of small promotional items to undermine their professional objectivity" and "In fact, researchers have found that the more gifts a physician receives, the more likely he or she is to believe that they do not influence behavior"). 
way influence their prescribing decisions." ${ }^{4}$ Only five percent of the respondents thought that the bounty "could possibly influence" their prescribing decisions, a prediction that was falsified by their own behavior, as discussed below. ${ }^{5}$

Codes of ethical conduct and commitments to evidence-based practice may not inoculate physicians from being influenced by financial conflicts of interest however. Indeed, such considerations may have a paradoxical effect, causing physicians to be overconfident in their own immunities. The domain in which physician discretion is constrained by black-and-white findings of biomedical science may be relatively small. According to a Congressional Budget Office review of the literature, arguably "less than half of all medical care is based on or supported by adequate evidence about its effectiveness." ${ }^{6}$

This paper explores the empirical evidence regarding the impact of financial relationships on the behavior of health care providers, specifically, physicians. Our methodology was to identify and synthesize peer-reviewed data addressing how financial conflicts of interest affect patient outcomes and health care costs. We sought to cover three main areas where conflicts of interest arise and may have an observable effect on health care practices. First, we surveyed studies relating to physicians' roles as referrers, in situations where they may have ownership stakes

4. J. P. Orlowski and L. Wateska, "The Effects of Pharmaceutical Firm Enticements on Physician Prescribing Patterns," Chest 102, no. 1 (1992): 270-273.

5. Id.

6. Research on the Comparative Effectiveness of Medical Treatments: Issues and Options for an Expanded Federal Role, "2007 CBO REPORT" available at <http://www.cbo.gov/ftpdocs/88xx/doc8891/MainText.3.1.shtml> (last visited July 21, 2012) [citing Institute of Medicine, "Learning What Works Best: The Nation's Need for Evidence on Comparative Effectiveness in Health Care" available at <www.iom.edu/ebmeffectiveness $>$ (last visited July 21,2012)]. 
or other incentives. Second, we surveyed studies relating to physician/payer interactions, including insurance reimbursement schemes intended to reduce costs and pay-for-performance (P4P). Third, we surveyed studies relating to financial relationships between physicians and representatives from the drug and device industries.

Our focus is upon the behavior of individual physicians; we did not include studies of hospitals or other actors. ${ }^{7}$ We do not attempt to provide a comprehensive review of all this literature, but instead focus on studies published in high impact journals, systematic review articles, and newer and/or innovative research studies on this topic. Our goal is to inform the debate about what, if anything, should be done about conflicts of interests among health care providers.

\section{Referral Incentives}

A referral occurs when a physician recommends a particular course of action to a patient, and can include a range of services from simple laboratory tests to invasive surgery by a specialist. A conflict of interest may exist if the referring physician receives remuneration on the basis of the referral. Certain referral fee

7. For an example of this broader literature, see e.g., J. Kosecoff et al., "Prospective Payment System and Impairment at Discharge: The "Quicker-andSicker" Story Revisited," JAMA 264 no. 15 (1990): 1980-1983. (studying patients in 300 hospitals and finding that when Medicare switched to a prospective payment system in which hospitals were paid a fixed fee for each patient rather than based on the costs of care, patients were discharged sooner and in less stable condition); and M. Tickle et al., "Paying for The Wrong Kind of Performance? Financial Incentives and Behaviour Changes in National Health Service Dentistry," Community Dentistry and Oral Epidemiology 39, no. 5 (2011): 465-473 (examining a conflict of interest situation for dentists). 
arrangements have been banned by federal and state laws. ${ }^{8}$ For example, if a consulting physician directed a proportion of the patient's consulting fee to the referring physician in exchange for the referral, such an arrangement would be considered an illegal "kickback."

Though kickbacks are illegal, there are loopholes, ambiguities, and variations in enforcement that continue to commonly allow physicians to receive remuneration based upon whether and to whom they refer patients. Most notably are the self-referral situations. A physician may be a "self-referrer," if the physician both evaluates the patient's need for a diagnostic test or therapeutic intervention, , and bills the payer for the referred service as well. Such self-referral situations do have benefits, such as the convenience of one-stop-shopping for the patient. ${ }^{9}$ Yet they also create incentives for the physician to prescribe additional or more intensive care, which may not be in the patient's interests and may not be economically efficient. This section reviews evidence of whether these incentives change physician behavior.

\section{a. Self-Referral For Office Services}

Several studies have explored the behavior of physician self-referrers in the context of diagnostic radiology (MRIs, CTs, etc.), comparing the self-referrers' utilization to that of physicians who refer patients to independent imaging centers. The

8. For a discussion of these laws, see J. H. Krause, "Following the Money in Health Care Fraud: Reflections on a Modern-Day Yellow Brick Road," American Journal of Law and Medicine 36, nos. 2 \&3 (2010): 365-369 at 343-69.

9. See J. F. Burris and W. J. Mroczek, "Letter to the Editor," N. Engl. J. Med. 324, no. 19 (1991): 1371-1373. (responding to the Hillman 1990 article discussed infra at_). 
phenomenon of self-referral is not uncommon. A recent study of large data California dataset found that $33 \%$ of the physicians billing for magnetic resonance imaging (MRIs), 22\% of the physicians billing for computerized tomography (CT) scans, and $17 \%$ of the physicians billing for positron emitted technology (PET) scans were "self-referrers." 10 Notably, of the self-referrers, $61 \%$ of the physicians billing for MRIs and 64\% of those billing for CTs did not "own" the equipment—instead, these physicians were "involved in the lease or payment-per-scan referral arrangements that might violate federal and state laws."11 Do these self-referring physicians order more scans, all other things being equal, than physicians who do not profit from their own referral decisions?

In 1992, Hillman and colleagues studied an insurance claims database, and compared frequency and costs of diagnostic imaging between physicians who owned the equipment (self-referring) and those physicians who referred to independent radiologists, where there was no financial incentive. ${ }^{12}$ Self-referring physicians used imaging tests at least four times more often than radiologistreferring physicians. ${ }^{13}$ Charges per-image were also usually higher for the selfreferring physicians. In another study using another insurance claims database and assessing a broader range of clinical presentations, Hillman and colleagues

10. J. M. Mitchell, "The Prevalence of Physician Self-Referral Arrangements After Stark II: Evidence from Advanced Diagnostic Imaging", Health Affairs 26 no. 3, (2007):415.

11. Id.

12. B. J. Hillman et al., "Frequency and Cost of Diagnostic Imaging in Office Practice-A Comparison of Self-Referring and Radiologist-Referring Physicians," $N$. Engl. J. Med. 323, no. 23 (1990): 1604-1608.

13. Id. This result was statistically significant at the .05 level, as are all other results discussed in this article, unless otherwise noted. 
compared physicians who owned imaging technology with those who did not, and found that self-referrers generated 1.6 to 6.2 times higher average imaging charges per episode of medical care than physicians who referred to independent radiologists. ${ }^{14}$

In 2011, Shreibati and Baker examined the behavior of "orthopedists and primary care physicians who begin billing for the performance of MRI procedures, rather than referring patients outside of their practice for MRI." 15 The dataset allowed the researchers to track the way the physicians practice styles changed upon buying an MRI, and they found that self-referring physicians "appear to change their practice patterns such that they use more MRI for their patients with low back pain."16 The scale of the change was quite large in relative terms: a $32 \%$ increase in utilization for primary care physicians, conditional upon purchasing an MRI machine. ${ }^{17}$ This pre-post design, with controls for physician-level and patient-level factors, allows a strong inference of causation. The new conflict of interest appeared to bias prescribing behaviors. The authors also found that, "these increases in MRI use appear to lead to increases in low back surgery receipt and health care spending among patients of orthopedic surgeons, but not of primary care physicians," perhaps because only the orthopedic surgeons were also in a self-referral situation

14. B. J. Hillman et al., "Physicians' Utilization and Charges for Outpatient Diagnostic Imaging in a Medicare Population," JAMA 268 (no. 15) (1992): 20502054.

15. J. B. Shreibati and L. C. Baker, "The Relationship Between Low Back Magnetic Resonance Imaging, Surgery, and Spending: Impact of Physician SelfReferral Status," Health Services Resource X, 46, no. 5 (2011): 1362-81. <http://onlinelibrary.wiley.com/doi/10.1111/j.1475-6773.2011.01265.x/full.> (last visited July 21,2012).

16. Id.

17. Id. at 11. 
with regard to surgery. ${ }^{18}$ The study did not examine patient outcomes, leaving open the possibility that the increase in MRI scans was salutary for patients. Still, as the authors note, their study focused on MRIs for "patients with nonspecific low back pain, for which [national practice] guidelines in many cases recommend against their use in many cases." 19

A 2011 JAMA study examined physicians' rates of ordering cardiac stress test procedures by analyzing national health insurance data for 17,847 patients who had coronary revascularization. ${ }^{20}$ Some physicians own their own cardiac stress testing equipment, and thus, can bill for professional and technical fees. Other physicians have no such conflicting interest because they must refer their patients for the testing elsewhere. Shah and colleagues used logistic regression models to compare the practice patterns of the self-referrers versus those who referred elsewhere, and even after statistical controlling for physician and patient factors, found that "the adjusted odds ratios (ORs) of nuclear stress testing among patients treated by [selfreferring] physicians were 2.3 " times that of "physicians who did not bill for testing," a highly significant result. ${ }^{21}$ The disparity in practice patterns was even greater for stress echocardiography, where the odds of self-referrers using the procedure were 12.8 times that of physicians without such a conflicting interest. Clinical practice guidelines do not recommend the routine use of these expensive

\section{Id.}

19. Id. at 16.

20. B. R. Shah, et al. "Association Between Physician Billing and Cardiac Stress Testing Patterns Following Coronary Revascularization," JAMA 306, no. 18 (2011): 1993-2000.

21. Id. at 1993. 
tests. $^{22}$ Aside from the expense, the nuclear stress tests expose patients to ionizing radiation and the risk of false-positive test results, which lead to further risky procedures. One limitation of this sort of observational study is the potential for a selection bias, or reverse-causation. It is possible, indeed plausible, that the physician's preference for prescribing the test more often causes him to purchase the equipment. That effect could be instead of, or in addition to, the purchase creating a financial interest that then causes a preference for using the equipment more often.

Oncologists are also in self-referral situations. Unlike most other medical specialties that rely on independent pharmacies to dispense drugs, oncologists often dispense intravenous chemotherapeutic agents themselves. For oncologists, choosing to administer chemotherapy rather than, say, referring a patient to hospice care, results in more compensation for the oncologist, and the choice of some particular intravenous drugs may result in higher profits than others. In 2003, Medicare changed its reimbursement for chemotherapy to reduce payments for these products, which also led to a change in the relative profit margins for some drugs over others. Jacobsen and colleagues examined the impact of the change in Medicare rules using a dataset with a quarter of a million cancer patients and comparing oncologists' behavior before and after the reform. ${ }^{23}$ They found that oncologists began prescribing chemotherapy $10 \%$ more often, for newly diagnosed

22. Id at 1994.

23. M. Jacobsen et al., "How Medicare's Payment Cuts for Cancer Chemotherapy Drugs Changed Patterns of Treatment," Health Affairs 29, no. 7 (2010): 1391-1399. 
lung cancer patients. ${ }^{24}$ One explanation is that oncologists sought to maintain their level of income by moving from a margin strategy to a volume strategy, so the additional prescriptions offset the lower profits per prescription. Jacobsen and colleagues also observed a shift between oncologists' choice of cancer drugs, towards drugs that became more profitable after the switch. The authors observed continued use of drugs like docetaxel, which maintained high marginal reimbursement rates, but a dramatic reduction in prescriptions of paclitaxel, whose reimbursement rates were cut. ${ }^{25}$ Jacobsen and colleagues did not assess the impact of these changes on patients or on net healthcare costs, but these data support the conclusion that oncologists' conflicts of interests appeared to drive a significant part of their behavior, in addition to whatever clinical concerns may have motivated them.

A 2012 study examined urologists who referred patients to themselves for pathology reviews of prostate biopsies, compared to urologists who instead sent specimens to independent pathologists. ${ }^{26}$ A self-referring urologist gets additional

\section{Id. at 1396.}

25. Id. See also C.L. Bennett et al., "The Association Between Physician Reimbursement in the US and Use of Hematopoietic Colony Stimulating Factors as Adjunct Therapy for Older Patients with Acute Myeloid Leukemia: Results from the 1997 American Society of Clinical Oncology Survey," Annals Of Oncology 10, no.11, (1999): 1355-1359.(finding that "reimbursement considerations are one of the most consistent determinants of use of" colony stimulating factors for treatment of leukemia); and S. P. Elliott et al., "Reduction in Physician Reimbursement and Use of Hormone Therapy in Prostate Cancer," Journal of the National Cancer Institute 102, no. 24 (2010): 1826-1834 (finding that excessive use of androgen suppression therapy was reduced when the 2003 Medicare Modernization Act reduced reimbursement for such therapy).

26. J. Mitchell, “Urologists' Self-Referral for Pathology Of Biopsy Specimens Linked To Increased Use And Lower Prostate Cancer Detection," Health Affairs 31, no.7 (2012): 741. 
income by ordering more specimens to be reviewed per biopsy. Using Medicare claims data, Mitchell found that self-referring physicians "billed Medicare for 4.3 more specimens per prostate biopsy than the adjusted mean of 6 specimens per biopsy that non-self-referring urologists sent to independent pathology providers, a difference of almost 72 percent."27 Strikingly, Mitchell's regression analyses revealed that urologists who did not self-refer found cancer twelve percent more often than the self-referrers. She concluded that, "financial incentives prompt selfreferring urologists to perform prostate biopsies on men who are unlikely to have prostate cancer."28 Mitchell acknowledged that since urologists self-selected to become self-referrers, and did so at a time outside the range of her dataset, the potential for causal inference was weaker in her study than it otherwise could have been, if she had been able to conduct a randomized trial or a differences-indifferences analysis. ${ }^{29}$

\section{Id., at 741.}

28. Id.

29. Id. at 744. For additional research examining self-referrals in the urology specialty see H. J Tan, "Use of Ureteroscopy Before and After Expansion of Lithotripter Ownership in Michigan," Urology 78, no. 6 (2011): 1287-91. (finding that physician ownership of lithiotripters did not decrease utilization of the substitute procedure, ureteroscpy); J.M. Hollingsworth, S.L. Krein, J.D. Birkmeyer et al., "Opening Ambulatory Surgery Centers and Stone Surgery Rates in Health Care Markets," Journal of Urology 184, no. 3 (2010): 967-971. J.M. Hollingsworth, Z. Ye, S.A. Strope et al., "Urologist Ownership of Ambulatory Surgery Centers and Urinary Stone Surgery Use," Health Service Research 44, no. 4 (2009): 1370-1384. 


\section{b. Referral to Physician-owned Centers}

Conflicts of interest also arise when a physician refers a patient to a provider outside her own office, but the physician nonetheless has a financial stake in that provider. This is a slightly less direct form of self-referral.

In a 1992 JAMA article, Mitchell and Scott reported on the effects of physician ownership of freestanding physical therapy and rehabilitation facilities and found that visits per patient were $39 \%$ to $45 \%$ higher in facilities owned by referring physicians. ${ }^{30}$ Both gross and net revenue per patient were $30 \%$ to $40 \%$ higher in such facilities. ${ }^{31}$

In a 1992 NEJM study, Swedlow and colleagues analyzed the effects of physician self-referral on three high-cost medical services covered under California's workers' compensation system, including physical therapy, psychiatric evaluation, and MRI scans. ${ }^{32}$ They compared the patterns of physicians who

30. J. M. Mitchell and E. Scott, "Physician Ownership of Physical Therapy Services: Effects on Charges, Utilization, Profits, and Service Characteristics", JAMA 268, no.15 (1992): 2055.

31. In another study, drawing from two surveys of physical therapists, Mitchell and Sass sought to explore two alternative explanations as to why physicians purchase shares in physical therapy providers - to control the quality of services provided to the patients they refer or to profit from the physician's ability to steer patients by artificially inflating demand for a particular provider. J. M. Mitchell and T. R. Sass, "Physician Ownership of Ancillary Services: Indirect Demand Inducement or Quality Assurance?,", Journal of Health Economics 14, no. 3 X(1995): 263-89. The researchers found that "a physical therapy clinic that receives all of its referrals from physician owners treats a patient for approximately 50 percent more visits than a clinic that receives no referrals from owners." Id., at 285. Mitchell and Sass also observed that the differential is directly related to "increases in physician density, decreases in population density, and increases in the total number of owners," which they argued were factors facilitating demand inducement.

32. A. Swedlow et al., "Increased Costs and Rates of Use in the California Workers' Compensation System as a Result of Self Referral by Physicians," N. Engl. J. Med. 327, no. 21 (1992): 1502-1506. 
referred patients to facilities of which they were owners (self-referral group) to patterns of physicians who referred patients to independent facilities (independentreferral group). The study found that physical therapy was initiated 2.3 times more often in the self-referral group than in the independent-referral group. This additional use more than offset the slight decrease in cost per case. The mean cost of psychiatric evaluation services was significantly higher in the self-referral group (34\% higher for psychometric testing and $22 \%$ higher for psychiatric evaluation reports) and the total cost per case of psychiatric evaluation services was $26 \%$ higher in the self-referral group than in the independent-referral group. For the MRI data, the authors coded whether the scans were medically appropriate or medically inappropriate, based on the decisions of an independent utilization review firm, including an appeal process. They found that of all the MRI scans requested by the self-referring physicians, $38 \%$ were medically inappropriate, as compared to $28 \%$ of those requested by physicians in the independent-referral group. The conflicting interest not only changed physician behavior, but also changed it for the worse.

Similar studies have also focused on physicians who have financial interests in specialty hospitals to which they refer. Federal law allows physicians to refer patients to hospitals in which they own a stake, on the theory that "any referral made by an individual physician investor in a whole hospital would in theory generate inconsequential financial gains for the referring physician." 33 This theory is questionable, however, when the hospital is narrowly specialized to provide a

33. J. M. Mitchell, "Do Financial Incentives Linked to Ownership of Specialty Hospitals Affect Physicians' Practice Patterns?," Medical Care 46 no. 7 (2008): 732-7. 
particular type of services, in which the physician also happens to specialize. Even worse, these hospitals tend to "specialize in the provision of relatively profitable services, most notably orthopedic, spine, cardiac, or surgical procedures," which thereby create the most focused financial incentives for the referrer/owners, making the conflicts of interests most pronounced. ${ }^{34}$

In 2008, Mitchell studied the impact of physicians' ownership of specialty hospitals, comparing the behavior before and after some physicians purchased interests in the specialty hospital. Mitchell's data included the behavior of both the purchasing physicians, and others who did not purchase, which thereby allowed a (self-selected) control group for comparison. Mitchell found that the "introduction of financial incentives linked to ownership coincided with a significant change in the practice patterns of physician owners." ${ }^{35}$ A physician's establishment of an interest in a specialty hospital correlated with an increased frequency in use of surgery, diagnostic, and ancillary services at the specialty hospital by that physician. As one example of this dynamic: consider the ratio between simple spinal fusion surgeries (a less profitable procedure) to complex spinal fusion surgeries (a more profitable procedure). Prior to buying into the hospital, the future owners recommended the complex, profitable procedure to only $0.1 \%$ of their patients. After buying into the hospital, the owner physicians began recommending the more invasive and more profitable procedure to $6.51 \%$ of their patients. No such change was observed in the non-owners' behavior over the same period of time. This is a huge shift in

34. Id.

35. Id. 
relative terms: "The relative odds of receiving complex spinal surgery was 65 times higher after physicians acquired a financial stake in the specialty hospital." ${ }^{36}$

Finally, some physicians have developed similar interests in ambulatory care centers. In a 2008 Health Affairs article, Gabel and colleagues found that physicians at physician-owned ambulatory surgery centers were more likely than other physicians to refer "well-insured patients to their facilities and route Medicaid patients to hospital outpatient clinics." ${ }^{37}$ In a relevant subset, only 55\% of Medicaid patients were referred to physician owned ASCs while $92 \%$ of privately insured patients were referred to physician owned ASCs.

\section{Physician Salary and Financial Incentives}

This section reviews the evidence relating to insurer-based incentives for physicians-primarily fee-for-service vs. capitation reimbursement and the use of pay-for-performance bonuses-and how those incentives are related to patient care, outcomes, and costs.

36. Id., at 735. Similarly, in a 2005 article, Iglehart offered a case study documenting the impact of the opening of a specialty hospital in Oklahoma, near a university hospital. Iglehart reports that "the number of inpatients admitted for cardiac care plummeted at the university hospital after 16 surgeons and cardiologists on the clinical faculty began to refer all their patients to the specialty hospital as soon as it opened," resulting over \$11.6 million in lost income for the university hospital over two years. J. K. Iglehart, "The Emergence of PhysicianOwned Specialty Hospitals," N. Engl. J. Med. 352, no. 1 (2005): 78-84.

37. J. R. Gabel et al., "Where Do I Send Thee? Does Physician-Ownership Affect Referral Patterns to Ambulatory Surgery Centers?", Health Affairs 27, no. 3 (2008): w165. 


\section{a. Physician Reimbursement Systems}

Generally, there are three types of systems that are used to pay physicians in theUnited States. Physicians may receive a salary, which is not typically based directly upon the number of patients or upon the quantity or types of services provided. Alternatively, fee-for-service (FFS) payments reimburse for the services physicians provide to patients. Finally, a capitation (CAP) system provides a fixed payment to physicians for caring for each patient (or group of patients) for a fixed period of time, regardless of the services that patient utilizes. FFS may incentivize physicians to provide more services to patients, while CAP may lead physicians to use fewer services to treat patients, potentially resulting in underutilization. ${ }^{38}$ Providing more services to patients may lead to better diagnosis and treatment for some patients, but can also lead to over-treatment, or unnecessary medical intervention that carries significant risks and costs. Commentators like Marc Rodwin have noted, "[c]onflicts of interest in fee-for-service medicine are significant and intractable. Coupled with insurance, they have spawned a great deal of overuse of medical services." ${ }^{39}$ By contrast, under-treatment is dangerous because it may lead physicians to misdiagnose or not treat medical conditions, also resulting in harm to patients. As Rodwin argues, some insurers responded to over-treatment by seeking to "eliminate these problems by giving physicians incentives to refrain from performing services. Only one thing was overlooked: rewarding physicians for

38. R. P Ellis and T. G McGuire, "Provider Behavior Under Prospective Reimbursement: Cost Sharing and Supply," Journal of Health Economics 5, no. 2 (1986): 129-151. See also, T. McGuire, "Physician Agency, in Cuyler AC," J.P. Newhouse ed, Handbook of Health Economics (Amsterdam, North-Holland, 2000). 39. Rodwin, Marc A. Conflicts of Interest and the Future of Medicine: The United States, France, and Japan. (Oxford: Oxford University Press, 2011). 
using resources frugally does not eliminate financial conflicts of interest. It creates new conflicts with different effects." 40

Thus, the financial schemes imposed by insurers can create conflicts of interest for physicians. This can be dangerous for patients if financial incentives to reduce services lead not only to reduction in overuse of low-benefit services, but also to under-use of high-benefit services. Indeed, in a survey conducted by Shen and colleagues, physicians reported that they would be less likely to provide certain discretionary care under a CAP scheme compared to FFS, except when life-saving care is needed. ${ }^{41}$ By creating different remuneration schemes, physicians' goals may be split between their own financial self-interest and the best interests of their patients.

But does the empirical evidence support the claims that insurance incentives alter physician behavior? Some studies have been decidedly mixed. For example, Hennig-Schmidt, Selten and Wiesen used a controlled experimental design to assess the effect of financial incentives and physician behaviors. ${ }^{42}$ They asked medical students to allocate various quantities of medical services for patients with varying levels of health states in a hypothetical lab setting. The authors found that the study participants provided more services when incentivized under FFS than compared

40. Id.

41. J. Shen RA, R. Brook, G. Kominski, P. S. Albert and N. Wenger, "The Effects of Payment Method on Clinical Decision-Making: Physician Responses to Clinical Scenarios," Medical Care 42, no. 3 (2004): 297-302.

42. H. Hennig-Schmidt, R. Selten, and D. Wiesen, "How Payment Systems Affect Physicians' Provision Behaviour-an Experimental Investigation," Journal of Health Economics 30, no. 4, (2011): 637-646. 
with a CAP payment system. However, the medical needs of the patients also influenced the quantity of services provided.

In a 1990 New England Journal of Medicine article, Hemenway and colleagues studied for-profit ambulatory care centers that changed their compensation system from a flat hourly wage to a bonus-based system that incentivized physicians depending upon the gross income each generated. In this pre-test/post-test natural experiment, Hemenway found that incentivized doctors increased the number of laboratory tests performed per patient visit by $23 \%$ and increased number of $x$-ray films per visit by $16 \%{ }^{43}$

Devlin and Sarma analyzed data from the 2004 Canadian National Physician Survey, and found that family practice physicians paid using FFS conducted more patient visits per week than physicians paid by other remuneration schemes; suggesting again that physicians do respond to financial incentives. ${ }^{44}$ Importantly, this was not a randomized trial; physicians self-selected into the differing reimbursement schemes. The control and treatment arms were thus unalike: “... the physicians who choose alternative remuneration would appear to have characteristics that would result in them seeing more patients per week ... relative to FFS physicians." This demonstrates that positive selection bias may be a factor, if physicians have a choice between remuneration schemes. Additionally, female physicians tended to see fewer patients per week, whereas married physicians saw

43. D. Hemenway et al., "Physicians Responses to Financial IncentivesEvidence from a For-Profit Ambulatory Care Center," N. Engl. J. Med. 322, no. 15, (1990): 1059-63.

44. R. A. Devlin and S. Sarmab, "Do Physician Remuneration Schemes Matter? The Case of Canadian Family Physicians," Journal of Health Economics 27, no. 5, (2008): 1168-1181. 
more patients per week, and age was also a statistically significant factor: for example, after age 45 , physicians tended to see fewer patients per week. Additionally, being part of a group practice also significantly contributed to patients seen per week, in addition to several patient characteristics. These findings suggest that while financial incentives do play a role in physicians' behaviors, patient needs and other contextual factors also play a significant role in physician decisionmaking.

Based on studies like these, some systematic reviews have concluded that the relationship between financial incentives and physician practice is not uniformly direct. ${ }^{45}$ Chaix-Courturier and colleagues conducted a systematic review of studies addressing the relationships between financial incentives and physician practice patterns. From the 89 articles that met the inclusion criteria - including eight randomized controlled trials - the authors found that many factors may play an equal or greater role than finances in determining physicians' practice, including the clinical settings and organizational factors, demographics and the clinical needs of patients. Town and colleagues conducted a focused review of the effect of various economic incentives (including FFS schemes and bonus structures) on physicians' delivery of preventive care services (such as immunizations, cancer screening and other preventive services) in 2005.46 In this review, only six studies met inclusion criteria, and only one study found a statistically significant relationship between

45. C. Chaix-Couturier et al., "Effects of Financial Incentives on Medical Practice: Results from a Systematic Review of The Literature and Methodological Issues," International Journal of Quality in Health Care 12, no. 2 (2000): 133-142. 46. R. Town et al., "Economic Incentives and Physicians' Delivery of Preventive Care," American Journal of Preventive Medicine 28, no.2 (2005): 234-240. 
financial incentive and increase in preventive services to patients. Indeed, the authors of a 2011 Cochrane Review concluded, “[d]espite the popularity of these [financial incentive] schemes, there is currently little rigorous evidence of their success in improving the quality of primary care." 47

However, such negative results should not be interpreted to mean that financial incentives do not change physicians' behaviors. For example, small rewards were commonly used in the reviewed studies, indicating the future researchers may want to assess the effects of larger and different forms of incentives. Another significant limitation of this review is that the underlying studies are often of poor methodological quality, and/or the types of incentives and outcomes were so different, that it is difficult to make conclusions about the impact of incentives generally.

While it is tempting to conclude from these results that physician/insurer financial incentives are not a leading driver of physician behavior, more recent studies in this area incorporating alternative methodological designs show the power of these conflicts of interest. Echevin and Fortin incorporated a natural experimental design, taking advantage of a policy reform in Quebec, Canada to investigate physician specialist incentives. ${ }^{48}$ The province changed its rules to permit physician groups to choose whether to participate in a mixed compensation scheme (MC) that provided a fixed per diem with a reduced fee for services, or to

47. A. Scott et al., "The Effect of Financial Incentives on The Quality of Health Care Provided By Primary Care Physicians," The Cochrane Collaboration, The Cochrane Library, Issue 9 (2011):

48. D. Echevin and B. Fortin, "Physician Payment Mechanisms, Hospital Length of Stay and Risk of Readmission: A Natural Experiment," SSRN eLibrary (2011). 
stay in a traditional FFS system instead. The physicians in the MC group were paid more for their time in the clinic, and less for the quantity of services provided than physicians under FFS. About half of the physician groups choose each condition. The authors predicted that MC may result in improved quality of care compared to FFS, and the results generally supported this prediction. Patients of the physicians in the MC condition showed an increased hospital stay of approximately 0.71 days (a 10.8\% increase) compared to the fee for service group with no difference in readmission rates between the two groups. The authors argued that this longer hospital stay indicated an improvement in the quality of care; physicians are seemingly spending more time with patients, but patients are not receiving more services (compared to the FFS group). Most importantly, these patients are not suffering negative health effects as a result of MC given that they are not being readmitted to the hospital. This study supports the theoretical claim that physicians are influenced by insurers' incentives, and that patient care may change as a result. The investigators found improvement in quality of care when physicians moved away from a fee for service (FFS) system, suggesting that the FFS system may represent a conflict of interest that negatively biases physician decisions.

\section{b. Effect of Pay-for-Performance Bonuses}

A more recent wave of research explores the role of pay-for-performance (P4P) programs and various insurance reimbursement schemes. P4P programs have been proposed by the Institute of Medicine, Centers for Medicare and Medicaid Services and other entities, including many private insurance companies, as an important 
way to improve health care quality and improve patient outcomes. ${ }^{49} \mathrm{P} 4 \mathrm{P}$ programs provide providers with financial incentives to improve the quality of care of their patients. ${ }^{50}$ Typically, these quality indicators are process measures of quality focusing on the prevention of disease or adherence to clinical care guidelines. Since such procedures are usually designed with the best interests of patients in mind, P4P may help improve patient outcomes.

However, there is limited evidence that P4P actually improves quality of care. ${ }^{51}$ The most recent literature review is a Cochrane Report of 32 studies evaluating the effectiveness of various financial incentives, including P4P, fee-forservice and capitation payments. ${ }^{52}$ The authors conclude:

When looking at the effect of [various types of] financial incentives overall across categories of outcomes, they were of mixed effectiveness on consultation or visit rates (improving 10/17 outcomes from three studies in two reviews); generally effective in improving processes of care (improving 41/57 outcomes from 19 studies in three reviews); generally effective in improving referrals and admissions (improving 11/16 outcomes from 11 studies in four reviews); generally ineffective in improving compliance with guidelines outcomes (improving 5/17 outcomes from five studies in two reviews); and generally effective in improving prescribing costs outcomes (improving 28/34 outcomes from 10 studies in one review).

49. K.J. Mullen, R.G. Frank and M.B. Rosenthal, "Can You Get What You Pay for? Pay-for-Performance and The Quality of Healthcare Providers," The RAND Journal of Economics 41, no. 1 (2010): 64-91; Testimony of Meredith B. Rosenthal, Ph.D.: Hearing on Examining Pay-for-Performance Measures and Other Trends in Employer-Sponsored Health Care, U.S. House Subcommittee on Employer-Employee Relations (2005).

50. IOM, 2006, "Rewarding Provider Performance: Aligning Incentives in Medicare, in Press" NA (ed). Washington D.C., Institute of Medicine (2006).

51. See G. Flodgren et al,, "An Overview of Reviews Evaluating The Effectiveness of Financial Incentives in Changing Healthcare Professional Behaviours and Patient outcomes," in Collaboration TC (ed), The Cochrane Library (2011); Mullen, Frank and Rosenthal, supra note 49, at 85;

52. Flodgren et al., supra note 51, at 2. 
It is important to note that the quality ratings of the 32 studies included in this review were of either "low" or "moderate" quality, highlighting the need for additional, higher-quality, research on the use of financial incentives in health care. However, other reviews have also found that incentivizing physicians to improve patient outcomes, may not, in fact, be as effective as proponents of $\mathrm{P} 4 \mathrm{P}$ have hoped. 53

There are also concerns that pay-for-performance financial incentives might lead to worse patient outcomes. One concern is the potential for cream-skimming, if physicians in a P4P regime forego care for risky patients, since the physicians may receive less money to care for such individuals. ${ }^{54}$ Physicians may skim by either deterring patients from forming a treatment relationship, or by terminating relationships once begun. The potential consequence of cream-skimming is that patients with complicated diseases, which could be time-consuming and/or expensive to treat, might have difficulty finding care providers. The fact that most risky patients are from underserved populations engenders particular concern. A 2011 study evaluated physicians' use of the Quality and Outcomes Framework (QOF), the P4P system for primary care physicians in the UK that allows physicians to designate certain patients to be excluded from their reported performance indicators. During the first three years of the QOF program, black and South Asian

53. See P. Van Herck et al, "Systematic Review: Effects, Design Choices, and Context of Pay-For-Performance in Health Care," Boston Medical Center Health Services Research 10, (2010): 247; B.Serumaga et al, "Effect of Pay for Performance on The Management and, Outcomes of Hypertension in The United Kingdom: Interrupted Time Series Study" Boston Medical Journal 342, (2011): d108; Scott et al., supra note 47 , at 3. incomplete information

54. P. P. Barros, "Cream-Skimming, Incentives for Efficiency and Payment System," Journal of Health Economics 22, no. 3 (2003): 419-443. 
patients were more likely to be excluded from performance reporting compared to white patients, as were patients who were less likely to achieve treatment targets and those who had co-morbidities or diabetes for over 10 years. The authors conclude that allowing physicians to exclude such patients from their performance indicators may exacerbate disparities for sicker and disadvantaged patients, given that physicians may focus their clinical efforts on the remainder of patients whose healthcare remains relevant to the physician's incentives, resulting in potentially less care for sick or disadvantaged patients. ${ }^{55}$ A review article of 22 studies assessing the impact of $\mathrm{P} 4 \mathrm{P}$ found that, "inequalities in chronic disease management between age, sex and ethnic groups persisted after" the introduction of P4P programs (mainly in the UK). ${ }^{56}$

A second concern about P4P programs is that, even while caring for particular patients, physicians involved will focus on performing the tasks that increase their income, diverting their attention away from other medically necessary care that is not part of financial incentive structures. Patients who need the interventions that are not covered by the P4P program may suffer as a result. This dynamic is referred to as a "negative spillover," because the policy has had unintended consequences on procedures outside the incentive program. However, such concerns have not yet been substantiated in empirical research. For example, Mullen and colleagues did not find negative (or positive) spillover effects of P4P

55. A. R.H. Dalton, R. Alshamsan, A Majeed et al., "Exclusion of Patients from Quality Measurement of Diabetes Care in The UK Pay-for-Performance Programme," Diabetic Medicine 28, no. 5 (2011): 525-531.

56. R. Alshamsan, "Impact of Pay for Performance on Inequalities in Health Care: Systematic Review," Journal of Health Services Research Policy 15, no. 3 (2010): 178-184. 
programs in their study of a large California HMO before and after implementation of a P4P program. ${ }^{57}$ Thus, evidence for cream-skimming and other adverse effects has limited empirical support and more research is needed to determine both the positive and the negative effects of P4P programs. ${ }^{58}$

In summary, financial incentive structures need to be carefully studied, designed, and modified in order to maximize the health of patients, but also to reduce potential conflicts of interest created by such structures that could unintentionally harm patients, or entire groups of patients.

\section{Relationships with the Pharmaceutical and Device Industries}

The effect of financial relationships on physician behavior can also be studied in the context of promotional inducements provided by pharmaceutical and device companies. Physicians learn about pharmaceutical agents in several ways, but a great deal of evidence demonstrates that commercial sources play a substantial role in shaping their knowledge and prescribing decisions. Pharmaceutical industry promotional tactics include manufacturer-sponsored presentations at conferences or continuing education programs, advertisements in medical journals and/or the lay press, and personal visits from manufacturers' sales representatives, called "detailers." A substantial number of physicians consider interactions with detailers to be their most influential source of information, and detailers' importance is

57. Mullen, Frank and Rosenthal, supra note 49, at 85.

58. In addition to the foregoing sources, see L. Peterson et al, "Does Pay-forPerformance Improve the Quality of Health Care?" Annals of Internal Medicine Vol 145, no.4 (2006): at 265-272. 
greatest among physicians who issue more prescriptions. ${ }^{59}$ In one study, $60 \%$ of physicians named commercial sources, such as detailers, as most influential in their first decision to prescribe a drug. ${ }^{60}$ Physicians' use of targeted prescriptions increases substantially after visits with sales representatives. ${ }^{61}$ Overall, many reviews have found a "strong, consistent, specific, and independent" association between physicians' behavior and their exposure to detailers. ${ }^{62}$

What accounts for the persuasive power of direct-to-physician pharmaceutical detailing? In addition to providing verbal descriptions of particular products and industry-developed sales pamphlets describing the benefits and risks of the product being sold, ${ }^{63}$ detailers often use the strategy of giving physicians various types of gifts. Social scientists have argued that these gifts can contribute to a positive view of sales representatives, and make them more receptive to the

59. P. A. Williams, R. Cockerill and F. H. Lowy, "The Physician as Prescriber: Relations Between Knowledge About Prescription Drugs, Encounters with Patients and the Pharmaceutical Industry, and Prescription Volume," Health and Canadian Society 3 (1995): 135-164.

60. M.Y. Peay and E. R. Peay, Social Science in Medicine 26, no. 12 (1988): 1183-1189.

61. D. Berings, L. Blondeel and H. Habraken, "The Effect of IndustryIndependent Drug Information on the Prescribing of Benzodiazepines in General Practice," European Journal of Clinical Pharmacolology 46, no. 6 (1994):501-505. See also, M. Y. Peay and E. R. Peay, "Innovation in High Risk Drug Therapy," Social Science in Medicine 39 no. 1, (1994): 39-52.

62. A. Wazana, "Physicians and The Pharmaceutical Industry: Is A Gift Ever Just A Gift?," JAMA 283, no. 3, (2000): 373-380. P. Manchanda, E. Honka, "The Effects and Role of Direct-to-Physician Marketing in the Pharmaceutical Industry: An Integrative Review," Yale Journal of Health Policy Law and Ethics 5, no. 2 (2005): 785-812. J. Lexchin, "Interactions Between Physicians and the Pharmaceutical Industry: What does the Literature Say?", Canadian Medical Association Journal 149, no. 10, (1993): 1401-1407.

63. E. E. Roughead, K. J. Harvey and A. L. Gilbert, "Commercial Detailing Techniques Used By Pharmaceutical Representatives to Influence Prescribing," Australia New Zealand Journal of Medicine 28 no. 3, X (1998): 306-310. 
information that detailers convey. ${ }^{64}$ There is substantial evidence on the power of this tool in driving physician prescribing practices. We found three general kinds of studies relevant to this question: those assessing the effect of direct financial inducements, those assessing the effect of free drug samples, and those assessing physicians' perception of the effect of marketing.

\section{a. Direct Financial Inducement in Pharmaceutical Promotion}

Drug and device promotional representatives have a number of direct inducements available to help drive prescribing, including food or beverages in the workplace; honoraria for speaking; payment for consulting services; payment for service on a scientific advisory board or board of directors; payment in excess of costs for enrolling patients in industry-sponsored trials; costs of travel, time, meals, lodging, or other personal expenses for attending meetings; gifts received as a result of prescribing practices; free tickets to cultural or sporting events; and free or subsidized admission to meetings or conferences for which Continuing Medical Education (CME) credits were awarded. In a survey of nearly 3,000 primary care physicians in the US, approximately two-thirds (63.8\%) received drug samples, $70.6 \%$ food and beverages, $18.3 \%$ reimbursements, and $14.1 \%$ payments for professional services. ${ }^{65}$ In some specialties, such as radiation oncology, the

64. J. Dana and G. Loewenstein, "A Social Science Perspective on Gifts to Physicians from Industry," JAMA 290, no. 2 (2003): 252-255.

65. E. G. Campbell, S. R. Rao, C. M. DesRoches, L. I. Iezzoni, C. Vogeli, D. BolcicJankovic and P. D. Miralles, "Physician Professionalism and Changes in PhysicianIndustry Relationships from 2004 to 2009," Archives of Internal Medicine 170, no. 20 (2010):1820-1826. 
prevalence of accepting gifts among physicians approaches $100 \% .{ }^{66}$ The investigators who surveyed radiation oncologists found that academic physicians who accepted larger gifts were far more likely to disagree with policies that would end the practice of gift-giving.

American physicians are not alone in reporting receipt of such inducements. For example, in one recent survey of over 800 Australian physicians, 96\% were offered free food, $94 \%$ were offered items for the office, $51 \%$ were offered personal gifts, $50 \%$ were offered journals or textbooks, over three-quarters were invited to product launches, symposia or educational events, and $52 \%$ were offered subsidized travel to conferences. ${ }^{67}$ A similar survey of over 2,500 Japanese physicians found that most physicians received free stationery (96\%) and participated in industrysponsored CME events at the workplace (80\%) and outside the workplace (93\%), while nearly half accepted meals outside the workplace (49\%) and financial subsidies to attend CME events (49\%). ${ }^{68}$

Do these types of inducements affect prescribing or pharmaceutical use behavior? Chren and Landefeld conducted a nest case-control study addressing this question at a single university. They identified 40 physicians who had requested that a drug be added to the hospital's official formulary in the prior 21 months.

66. E. C. Halperin, P. Hutchison and R. C. Barrier, Jr., "A Population-Based Study of the Prevalence and Influence of Gifts to Radiation Oncologists from Pharmaceutical Companies and Medical Equipment Manufacturers," International Journal of Radiation Oncology, Biology, Physics 59, no. 5, (2004):1477-1483. ।

67. P. M. McNeill, I. H. Kerridge, D. A. Henry, B. Stokes, S. R. Hill, D. Newby, et al. "Giving and Receiving of Gifts between Pharmaceutical Companies and Medical Specialists in Australia," Internal Medicine Journal 36, no. 9, (2006): 571-578.

68. S. Saito, K. Mukohara and S. Bito, "Japanese Practicing Physicians' Relationships with Pharmaceutical Representatives: A National Survey," PLoS 5, One e12193 (2010). 
Eighty control physicians were randomly selected and all physicians were surveyed about their pharmaceutical marketing interactions. Physicians who had requested additions to the drug formulary were over five times more likely to have accepted money from companies to attend or speak at educational symposia or to perform research. When the authors examined the relationship between particular companies and the drugs they promoted, they found that physicians were nearly twenty times more likely than other physicians to have requested that drugs manufactured by specific companies be added to the formulary if they had accepted money from those companies. These associations were consistent in multivariable analyses controlling for potentially confounding factors including physician age, gender, appointment in the department of medicine, and number of patients seen per week. ${ }^{69}$

These results were consistent with another survey of almost 400 physicians that took place at seven Midwest teaching hospitals where faculty and house staff averaged 1.5 contacts per month with pharmaceutical sales representatives, and received free meals and other gift inducements. ${ }^{70}$ Free meals were found to be an independent predictor of self-reported changes in prescribing practices. Receipt of honoraria and research support were separate significant predictors of faculty requests for formulary addition of the pharmaceutical product that was the subject of the inducement. It is notable that both this study and the one by Chren and

69. M. M Chren and C. S. Landefeld, "Physicians' Behavior and Their Interactions with Drug Companies: A Controlled Study of Physicians Who Requested Additions to a Hospital Drug Formulary," JAMA 271, (1994): 684-689.

70. N. Lurie, E. C. Rich, D. E. Simpson et al., "Pharmaceutical Representatives in Academic Medical Centers," Journal of General Internal Medicine 5, no. 3 (1990): 240-243. 
Landefeld were performed before development of a Code of Ethics by PhRMA, the primary industry trade group for large pharmaceutical companies, which has led to the abatement of some of the most excessive types of inducements, such as vacations and other large-value gifts.

One type of financial inducement separately shown to have a particularly strong effect is sponsorship of Continuing Medical Education (CME) and payment for conference participation. Practicing physicians are required to undertake a certain amount of CME to maintain their medical license, although engaging in such education can be expensive and time-consuming. Thus, pharmaceutical manufacturers have frequently sponsored and organized CME activities without charging physicians for their participation. To encourage participation, these events occur in high-demand geographic locations, such as popular local restaurants. Pharmaceutical company-sponsored CME is a relatively common phenomenon; for example, in one survey of over a thousand physicians in the Edinburgh, Scotland, area, the investigators found that the pharmaceutical industry funded approximately half of the meetings and conferences attended by doctors, while onethird of the meetings would not have been attended if funding from the industry had not been available. ${ }^{71}$ A qualitative survey of prescribers conducted by health care marketing researchers found that, of all gifts discussed, the sponsoring of medical conference was particularly highly valued. They concluded that funding for conference strengthens "the physician's commitment to the financing company

71. P. Rutledge, D. Crookes, B. McKinstry and S. R. Maxwell, "Do Doctors Rely on Pharmaceutical Industry Funding to Attend Conferences and Do They Perceive That This Creates A Bias in Their Drug Selection? Results from A Questionnaire Survey," Pharmacoepidemiol Drug Safety 12 no. 8, (2003): 663-667. 
(possibly as a result of the company's increased legitimate power), thus increasing brand loyalty in the long term."72

Pharmaceutical company-sponsored CME events have a positive effect on prescribing. Bowman and Pearle investigated the effects of company-funded CME by conducting surveys of physicians before and after they attended three separate CME events. In each case, physicians reported increased prescribing ratios (as compared to other related products) of the specific drug made by the manufacturer that sponsored the events. ${ }^{73}$ Such findings were also demonstrated in a pre-/postdesign study of physicians who attended all-expenses-paid trips to popular vacation sites to attend symposia sponsored by a pharmaceutical company. The study assessed pharmacy inventory usage reports for the two drugs being promoted. The investigators found that prescriptions of one drug increased from a mean of 81 units before the symposium to 272 after the symposium, while usage of the other drug changed from 34 units before the symposium to 87 units after the symposium. These spikes in prescribing were also significantly different from the national usage patterns of the two drugs by comparable large hospitals and major medical centers over the same period of time. ${ }^{74}$ Though the study was performed before the PhRMA Code of Ethics mostly ended the specific inducements provided, the investigators

72. K. Campo, O. De Staebel, E. Gijsbrechts and W. van Waterschoot, "Physicians' Decision Process for Drug Prescription and the Impact of Pharmaceutical Marketing Mix Instruments", Health Marketing Quarterly 22, no. 4, (2005):73-107.

73. M. A. Bowman, D. L. Pearle," Changes in Drug Prescribing Patterns Related to Commercial Company Funding of Continuing Medical Education," Journal of Continuing Education in the Health Professions 8 no. 1, (1988): 13-20.

74. J. P. Orlowski and L. Wateska, "The Effects of Pharmaceutical Firm Enticements on Physician Prescribing Patterns," Chest 102, no. 1 (1992): 270-273. 
found that the alterations in prescribing patterns occurred even though the majority of physicians who attended the symposia reported that such enticements would not alter their prescribing patterns. These same practitioner denials of effect are common with present-day inducements, despite evidence that small gifts have at least as strong a social effect on physician behavior.

Another financial inducement that has been separately studied is the provision of free textbooks to medical students. Though medical students do not have the authority to prescribe drugs, pharmaceutical companies actively market to these trainees, ${ }^{75}$ perhaps to engender a positive rapport and lay the groundwork for future promotional activities. One study surveyed groups of fourth-year medical students who received a free textbook from a pharmaceutical company to determine whether they could recall the name of the book or the specific company that provided the gift. Only $25 \%$ of the named books were accurately associated with a pharmaceutical company or product. The largest cohort of respondents, all from a single medical school, also rated pharmaceutical sales representatives who conversed with them or gave them gifts as "helpful and informative," while reporting being "skeptical" of sales representatives who ignored them because they were students. The authors concluded that while gifts to medical students may not engender company-specific recall, attention paid to medical students by

75. K. E. Austad, J. Avorn and A. S. Kesselheim, "Medical Students' Exposure to and Attitudes About the Pharmaceutical Industry: A Systematic Review," PLoS Medicine 8, no. 5 (2011): e1001037. 
pharmaceutical representatives engenders goodwill toward the representatives and their messages. ${ }^{76}$

\section{b. Drug Samples and Physician Prescribing}

Drug samples are a second major route for industry influence. A drug sample is a small supply of a product provided free of charge to a physician's office, intended for subsequent distribution to patients. Drug samples have been promoted as a way of reducing costs of expensive medications for needy patients, however research shows that samples preferentially go to wealthier patients, ${ }^{77}$ physicians, or members of their staff, 78 and they do not adequately relieve the financial burden of drug costs on their recipients. ${ }^{79}$ Physicians also highly value receiving drug samples. A qualitative study of 67 general practitioners in the United Kingdom considered receiving samples to be one of the best reasons to interact with pharmaceutical sales representatives. ${ }^{80}$ However, pharmaceutical representatives point to drug samples as a strategic marketing tool intended to promote future

76.W. S. Sandberg, R. Carlos, E. H. Sandberg and M. F. Roizen, "The Effect of Educational Gifts from Pharmaceutical Firms on Medical Students' Recall of Company Names or Products," Academic Medicine 72, no. 10, (1997): 916-918.

77. S. L. Cutrona, S. Woolhandler, K. E. Lasser, D. H. Bor, D. McCormick and D. U. Himmelstein, "Characteristics of Recipients of Free Prescription Drug Samples: A Nationally Representative Analysis," American Journal of Public Health 98, no.2 (2008): 284-289.

78. D. Morelli and M. R. Koenigsberg, "Sample Medication Dispensing in A Residency Practice," Journal of Family Practitioners 34, no. 1, (1992): 42-48; J.M. Westfall, J. McCabe and R. A. Nicholas,. "Personal Use of Drug Samples by Physicians and Office Staff," JAMA 278, no.2 (1997): 141-143

79. G. C. Alexander, J. Zhang and A. Basu, "Characteristics of Patients Receiving Pharmaceutical Samples and Association Between Sample Receipt and Out-of-Pocket Prescription Costs," Medical Care 46, no.4 (2008): 394-402.

80. A. N. Thomson, B. J. Craig and P. M. Barham, "Attitudes of General Practitioners in New Zealand to Pharmaceutical Representatives," British Journal of General Practice 44, no. 382, (1994): 220-223 
prescriptions of a drug that is likely to be expensive, and possibly more so than other reasonable alternatives. ${ }^{81}$ At least seven studies have examined the role of drug samples in driving prescribing practices.

In one randomized trial, resident physicians serving in an inner-city primary care clinic were prospectively separated in two groups: usual practice including use of available free drug samples, and a promise not to use any free drug samples. Collecting a sample of nearly 400 therapeutic decisions made during the trial period, the investigators found that physicians with access to drug samples were more likely to write prescriptions for advertised drugs (35\% compared to $27 \%$ ) and less likely to choose over-the-counter drugs (25\% compared to $39 \%) .{ }^{82}$

Three retrospective studies have taken advantage of natural experiments to assess the role of drug samples. In one, segmented linear regression models were used to evaluate trends in prescribing after implementation of a policy prohibiting prescription drug samples (and pharmaceutical industry interactions) in a rural family practice clinic in central Oregon. In aggregate, use of promoted agents decreased by $1.4 \%$ while non-promoted branded agents increased by $3.0 \%$, although these changes were not statistically significant. The study had a number of limitations, including the highly selected sample of patients and prescriptions. However, the results showed significant changes in certain classes of drugs, such as

81. A. Fugh-Berman and S. Ahari, "Following the Script: How Drug Reps Make Friends and Influence Doctors," PLoS Medicine 4, no.X (2007): e150.

82. R. F. Adair and L.R. Holmgren, "Do Drug Samples Influence Resident Prescribing Behavior? A Randomized Trial," American Journal of Medicine 118, no. 8, (2005): 881-884. 
cholesterol-lowering drugs and antidepressants. ${ }^{83}$ Similarly, in a retrospective chart-review study of prescribing before and after imposition of a ban on drug samples at a hospital-based clinic, there was an increase in firstline antihypertensive use from $38 \%$ to $61 \%$ following prohibition of sample distribution. ${ }^{84}$ Finally, a retrospective study of three family practice residency programs with different baseline drug sample policies (not allowed vs. limited vs. unlimited) found a greater percentage of generic prescriptions and use of preferred drugs in the program with sample restrictions and the program with no samples. However, this result was limited to only 1 of 3 drug classes studied, and no change in the average cost per prescription was observed..$^{85}$

Survey data and one qualitative study have revealed consistent conclusions about the effect of drug samples. A survey published in 2000 of 154 internists and family practitioners at a single university-based clinic (85\% response rate) found that the availability of drug samples led physicians to dispense and subsequently prescribe drugs that differ from their preferred drug choice for the management of urinary tract infections, hypertension, and depression. ${ }^{86}$ A more recent survey of primary care practitioners in a single state (33\% response rate) found that $72 \%$ of

83. D. M. Hartung, D. Evans, D. G. Haxby, D. F. Kraemer, G. Andeen and L. J. Fagnan, "Effect of Drug Sample Removal on Prescribing in A Family Practice Clinic," Annals of Family Medicine 8, no. 5, (2010): 402-409.

84. J. M. Boltri, E. R. Gordon and R. L. Vogel, "Effect of Antihypertensive Samples on Physician Prescribing Patterns," Family Medicine 34, no. 10, (2002): 729-731.

85. D. Brewer, "The Effect of Drug Sampling Solicits on Residents' Prescribing," Family Medicine 30, no. 7 (1998): 482-486.

86. L. D. Chew, T. S. O’Young, T. K. Hazlet, K. A. Bradley, C. Maynard and D. S. Lessler, "A Physician Survey on Effect of Drug Sample Availability on Physicians' Behavior," Journal of General Internal Medicine 15, no. 7 (2000): 478-483. 
prescribers reported samples in their office. In a second survey, physicians without samples were more likely to prescribe first-line preferred medications when presented with scenarios calling for those products in the management of hypertension ( $91 \%$ vs. $70 \%, \mathrm{p}<0.01)$ and depression $(100 \%$ vs. $91 \%, \mathrm{p}=0.02) .{ }^{87} \mathrm{~A}$ series of personal interviews with 124 physicians in Australia conducted in the wake of meetings with pharmaceutical sales representatives investigated physicians' perceptions and attitudes about use of a newly approved and widely promoted drug. The authors found that those who received a sample of the drug were more likely to say that they now usually prescribed the drug over alternatives $(\mathrm{P}<0.006) .88$

These studies overall support a consistent effect of drug samples in driving prescribing practices. Drug samples provided to physicians by detailers lead physicians to prescribe drugs that differed from what otherwise would be their preferred drug choice, including more expensive, second-line drugs.

\section{c. Physicians' Perceptions about Drug and Device Marketing}

Physicians are often unaware of the substantial impact of manufacturer promotional activities on their practices. One of the first of such studies was published in 1982. In a random sample of primary care physicians, the investigators found that while physicians generally denied that information from commercial channels was an

87. R. G. Pinckney, A. S. Helminski, A. G. Kennedy, C. D. MacLean, L. Hurowitz and E. Cote, "The Effect of Medication Samples on Self-Reported Prescribing Practices: A Statewide, Cross-Sectional Survey," Journal of General Internal Medicine 26, no. 1, (2011): 40-44 .

88. M. Y. Peay and E. R. Peay, "The Role of Commercial Sources in the Adoption of A New Drug." Social Science in Medicine 26, no. 12 (1998): 1183-1189. 
important source of their drug information, their knowledge of drug properties was more consistent with sales information for these drugs than with the medical literature. ${ }^{89}$ In another study, $11 \%$ of the statements made by pharmaceutical representatives about drugs were scientifically inaccurate, and physicians generally failed to recognize the inaccurate statements. ${ }^{90}$ In one survey of 105 physicians-intraining at seven Canadian hospitals, a statistically significant correlation was found between a larger number of self-reported gifts received and the belief that discussions with pharmaceutical representatives did not affect prescribing. ${ }^{91}$ The failure of physicians to recognize detailers' influence on their prescribing practices may be explained by research showing that detailers' free samples, gifts, and lunches make it difficult for physicians to be aware of the resulting biases in their own decision making. ${ }^{92}$

\section{Discussions and Conclusions}

Our review has found evidence that financial relationships bias physician decisions to different degrees in all three areas we explored: the payments to referrers, the incentives created by health insurers, and the largesse provided by the

89. J. Avorn, M. Chen and R. Hartley, "Scientific Versus Commercial Sources of Influence on The Prescribing Behavior of Physicians," American Journal of Medicine 73, no. 1, (1982): 4-8..

90. M. G. Ziegler, P. Lew and B. C. Singer, "The Accuracy of Drug Information from Pharmaceutical Sales Representatives," JAMA 273, no. 16, (1995): 1296-1298.

91. B. Hodges, "Interactions with the pharmaceutical industry," CMAJ 153, no. 5, (1995): 553-559.

92. D. Blumenthal, "Doctors and Drug Companies," N. Engl. J. Med. 351, no. 18, (2004): 1885-1890.. 
drug and device industries. It is worth mentioning that many of the studies reviewed herein did not even discuss or refer to the conflict of interest problem as such, even while documenting such a dynamic. ${ }^{93}$

Each of the referenced studies has limitations. Most notably, many of the studies were observational, rather than randomized controlled trials, making the inference of causation difficult. In these situations, it is possible that there are other causal factors driving the observed results, but many of the investigators also made reasonable efforts to identify and control for those factors.

Of course, the data presented here generally relied upon means and other measures of central tendency. We cannot say that all physicians are equally susceptible to financial interests. ${ }^{94}$

A more fundamental problem is that, while several of the studies were able to establish a baseline of appropriate care using practice guidelines or independent reviews, and thus demonstrate that the financial interest was contrary to the interests of the patient, many other studies failed to specify the optimal rate for a given physician's behavior. Thus, for some of the studies it is possible that, even if financial relationships are changing physician behaviors, they are changing them for the better in certain situations. It may be that most patients get MRIs too rarely, and that self-referring physicians are actually approximating the optimal rate of

93. See e.g., Shreibati and Baker supra note 15.

94. See Stefan Sohn, "Intrinsic Motivational Drivers in Medical Networks from a Neuroscientific Perspective," Journal of Neuroscience Psychology and Economics Vol 4 no. 3, (2011): 192 (studying physicians and finding four different primary motivational factors). 
prescriptions, while other physicians are lagging. This sort of argument will be more plausible in some clinical contexts than others.

Our findings have relevance to four audiences - scholars, physicians, patients, and policymakers. First, we have identified areas where the evidence-base is strong, and areas where further research is warranted. Although there can now be little doubt that physicians, like all human beings, respond to incentives, further research is warranted to document the impact on patient outcomes and health care costs, especially in the health insurance sector. Where possible, randomized controlled trials should also be implemented to help account for other causal pathways.

Second, the research studies described herein should go some distance in dispelling the sense of denial that continues to infect the thinking of physicians. ${ }^{95} \mathrm{~A}$ richer understanding of the problem may cause some health professionals to better manage or avoid conflicting interests, in order to protect their own self-respect and sense of professionalism. Within the profession, social norms - and social shaming when they are violated - are likely to be part of the ultimate solution to these problems. ${ }^{96}$

Third, to the extent that patients become more aware of how their physicians' financial relationships distort their advice, that knowledge is also likely

95. See notes 3-5 supra.

96. For an analysis of this dynamic in the context of legal professionalism, see W. Bradley Wendell, "Nonlegal Regulation of the Legal Profession: Social Norms in Professional Communities," Vanderbilt Law Review 54, no. 5 (2001):1955 
to change the doctor-patient relationship. ${ }^{97}$ To the extent that this knowledge allows patients' to better calibrate their reliance on their physicians, decreasing their degree of deference when physicians are making recommendations that are plausibly infected by bias, this may be a good thing in a sub-optimal world where such conflicts of interests continue persist. This loss of trust is dangerous, however, if patients are unable to distinguish between the biased decisions and the unbiased decisions, and if they have no alternative sources of unbiased advice. ${ }^{98}$

Fourth, this clear evidence that conflicts of interest contribute to bias, even if it is not comprehensive or immune to criticism, should reinvigorate policymakers' efforts to manage or ban conflicting interests. Such policies are not themselves costless - since almost any reimbursement system can create conflicts on the margins and relationships with industry can be valuable - the present evidence shows that cost of inaction is also quite high. Conflicting interests create substantial distortions in the decisions made by health care professionals.

\section{$\underline{\text { Acknowledgments }}$}

The authors thank John G. Connolly (Brigham and Women's Hospital), Jennifer Cook (University of Arizona), and Maureen Garmon (University of Arizona) for their assistance with the research and editing of this paper. The authors conducted this

\footnotetext{
97. See generally, David Mechanic and Mark Schlesinger, "The Impact of Managed Care on Patients' Trust in Medical Care and Their Physicians," JAMA Vol 275, no.21 (1996): 1693-1697.

98. See generally, C. T. Robertson, “Biased Advice," Emory Law Journal 60 no. 3 (2011):. 653.
} 
work while receiving research support by the Edmond J. Safra Center for Ethics at Harvard. 